\title{
RUSSIAN STATE TIME AND EARTH ROTATION SERVICE: OBSERVATIONS, EOP SERIES, PREDICTION
}

\author{
M. Kaufman, S. Pasynok \\ 141570, VNIIFTRI, Mendeleevo, Moscow reg., Russia \\ e-mails: mark@imvp.ru, pasynok@imvp.ru
}

\begin{abstract}
Russian State Time, Frequency and Earth Rotation Service provides the official EOP data and time for use in scientific, technical and metrological works in Russia. The observations of GLONASS and GPS on 30 stations in Russia, and also the Russian and worldwide observations data of VLBI (35 stations) and SLR (20 stations) are used now. To these three series of EOP the data calculated in two other Russian analysis centers are added: IAA (VLBI, GPS and SLR series) and MCC (SLR). Joint processing of these 7 series is carried out every day (the operational EOP data for the last day and the predicted values for 50 days). The EOP values are weekly refined and systematic errors of every individual series are corrected. The combined results become accessible on the VNIIFTRI server (ftp.imvp.ru) approximately at $6 \mathrm{~h}$ UT daily.
\end{abstract}

Keywords: Earth rotation, EOP, GLONASS, GPS, VLBI, SLR.

\section{INTRODUCTION}

Russian State Time, Frequency and Earth Rotation Service is permanently functioning system of facilities and organizations incorporated into the common scientific, technical and metrological activity, which includes continuous reproduction, keeping and dissemination of the national time scale and also determination of Earth's orientation parameters (EOP).

The Main Metrological Center (MMC) of the Service is located in National Research Institute for Physical and Radio-technical Measurements (VNIIFTRI).

EOP evaluations are conducted during many decades in MMC. The astronomical observations were used as measurements data in the past; the satellite and VLBI measurements are used now. The measurements are provided in MMC every day and evaluated EOP values are operatively published in the bulletins accessible through the Internet.

\section{OBSERVATIONS PROCESSING}

In MMC processing of measurements results and evaluation of EOP are provided separately for each technique: GPS, SLR and VLBI. Regular operative EOP evaluations using GPS data are carried out on the basis of processing of phase measurements from 31 Russia stations (2009) and from neighboring states, participating in teamwork many years (see Table 1). 
Table 1. Station of the GPS measurements.

\begin{tabular}{|c|c|c|c|}
\hline Station & Location & Receiver & Days \\
\hline ARTU & Arti, Russia & ASHTECH Z-XII3 & 361 \\
\hline CHUM & Chumysh, Kazakhstan & ROGUE SNR-8000 & 361 \\
\hline CRAO & Simeiz, Ukraine & ROGUE SNR-8000 & 273 \\
\hline GLSV & Kiev, Ukraine & TRIMBLE 4000 SSI & 362 \\
\hline IRKJ & Irkutsk, Russia & JPS LEGACY & 361 \\
\hline IRKM & Irkutsk, Russia & ASHTECH UZ-12 & 361 \\
\hline IRKT & Irkutsk, Russia & ROGUE SNR-8000 & 338 \\
\hline KHAJ & Khabarovsk, Russia & JPS LEGACY & 355 \\
\hline KIT3 & Kitab, Uzbekistan & $\mathrm{AOA}$ SNR-8000 ACT & 332 \\
\hline MDVJ & Mendeleevo, Russia & NET-G3 & 365 \\
\hline MIKL & Mykolaiv, Ukraine & TRIMBLE 4700 & 361 \\
\hline MOBN & Obninsk, Russia & ASHTECH Z-XII3 & 339 \\
\hline NOVJ & Novosibirsk, Russia & JPS LEGACY & 363 \\
\hline NRIL & Norilsk, Russia & ASHTECH Z-XII3 & 276 \\
\hline NSSP & Yerevan, Armenia & ASHTECH UZ-12 & 319 \\
\hline NVSK & Novosibirsk, Russia & TRIMBLE 4700 & 339 \\
\hline PETP & Petropavlovsk-Kamchatky, Russia & ASHTECH Z-XII3 & 264 \\
\hline PETS & Petropavlovsk-Kamchatky, Russia & ASHTECH Z-XII3 & 362 \\
\hline POL2 & Bishkek, Kyrghyzstan & ASHTECH Z-XII3 & 361 \\
\hline POLV & Poltava, Ukraine & TRIMBLE 4700 & 363 \\
\hline PULK & Pulkovo, Russia & TRIMBLE $4000 \mathrm{SSE}$ & 365 \\
\hline SELE & Almaty, Kazakstan & ROGUE SNR-8000 & 357 \\
\hline SULP & Lviv, Ukraine & TRIMBLE 4700 & 364 \\
\hline SVTL & Svetloe, Russia & LEICA SR520 & 359 \\
\hline TIXI & Tixi, Russia & ASHTECH Z-XII3 & 281 \\
\hline UZHL & Uzhgorod, Ukraine & TRIMBLE 4000 SSI & 285 \\
\hline YAKT & Yakutsk, Russia & ASHTECH Z-XII3 & 332 \\
\hline YSSK & Yuzhno-Sakhalinsk, Russia & ASHTECH Z-XII3 & 358 \\
\hline ZECK & Zelenchukskaya, Russia & $\mathrm{AOA} \quad \mathrm{SNR}-8000 \mathrm{ACT}$ & 357 \\
\hline ZWE2 & Zwenigorod, Russia & $\mathrm{AOA}$ SNR-8000 ACT & 351 \\
\hline
\end{tabular}

The processing of measurements and EOP evaluations are carried out using the BERNESE GPS software version 5.0 created in Astronomical Institute of the University of Bern (AIUB, Switzerland). The actual algorithm was entered in 2006. It is based on the socalled method of Precise Point Positioning (PPP). This method is based on use phase measurements for the navigating task solution with known precise satellites coordinates and onboard clocks biases. Then the values of UT1 and pole coordinates are calculated using the calculated instantaneous coordinates of stations and their catalogue values. Processing is carried out separately for each daily session of measurements.

For EOP evaluation using satellite laser ranging (SLR) technique, the SLR observations from 31 stations (2009) of SLR international network are used. Observations of LAGEOS-1 and LAGEOS-2 satellites are processed on 3-daily arcs separately, and then the common values of pole coordinates $x, y$ and length of day $L O D$ are formed. The scale of $U T 1$ is build by means of cumulative summation of $L O D$ values adding empirical amendments. 
EOP evaluations from VLBI technique are carried out with the help of software package OCCAM version 5.0, specially adapted to the rapid service mode. Observation data of international programs NEOS-A, CORE, IRIS-S, INT-1,2 etc are used. Files of observations in NGS format get out from the international database. They differ in structure of stations network, the size and type of aerials, duration of measuring sessions (from 1 till 24 hours) and periodicity of their performance (for example, once a week or every day). Daily sessions provide evaluation of five EOP parameters (pole coordinates $x$ and $y, U T 1$, amendments to nutation angles $d \psi$ and $d \varepsilon$ ), and hourly sessions - only UT1.

Table 2 characterizes the accuracy of EOP values evaluated for each technique.

Table 2. Accuracy of individual EOP series evaluated in MMC.

\begin{tabular}{|c|c|c|c|c|c|c|c|}
\hline \multirow{3}{*}{ Technique } & \multirow{3}{*}{ Estimation } & \multicolumn{3}{|c|}{ RMS } & \multicolumn{3}{|c|}{ Bias } \\
\hline & & \multirow{2}{*}{$\begin{array}{l}\text { UT1 } \\
(\mathrm{ms})\end{array}$} & $\mathrm{x}$ & $\bar{Y}$ & \multirow{2}{*}{$\begin{array}{l}\text { UT1 } \\
(\mathrm{ms})\end{array}$} & $\mathrm{x}$ & $\mathrm{y}$ \\
\hline & & & \multicolumn{2}{|c|}{ (mas) } & & \multicolumn{2}{|c|}{ (mas) } \\
\hline \multirow[t]{2}{*}{$\overline{\text { GPS }}$} & internal & 0.025 & 0.22 & 0.18 & & & \\
\hline & external & 0.019 & 0.12 & 0.17 & -0.015 & -0.01 & -0.80 \\
\hline \multirow[t]{2}{*}{ SLR } & internal & 0.006 & 0.06 & 0.06 & & & \\
\hline & external & 0.156 & 0.80 & 0.61 & +0.327 & -0.60 & -0.29 \\
\hline \multirow[t]{2}{*}{ VLBI } & internal & 0.001 & 0.06 & 0.07 & & & \\
\hline & external & 0.025 & 0.41 & 0.32 & +0.003 & +0.19 & -0.15 \\
\hline
\end{tabular}

\section{COMBINED EOP}

Resulting daily EOP(RU) are calculated in MMC by the combination of the seven independent individual EOP series provided by following three Russian analysis centers: MMC (VNIIFTRI), IAA (Institute of Applied Astronomy) and IAC (Information-Analytical Center of Russian Space Agency). The list of these series is summarized in Table 3.

Table 3. The individual EOP series used for combination.

\begin{tabular}{|c|c|c|l|l|}
\hline № & $\begin{array}{c}\text { Analysis } \\
\text { Center }\end{array}$ & $\begin{array}{c}\text { Observation } \\
\text { technique }\end{array}$ & \multicolumn{1}{|c|}{ EOP values } & \multicolumn{1}{|c|}{ Points of measurements } \\
\hline 1 & MMC & SLR & $x, y, U T 1$ & International network \\
\hline 2 & MMC & GPS & $x, y, U T 1$ & Russian \\
\hline 3 & MMC & VLBI & $x, y, U T 1, d \psi, d \varepsilon$ & International + 3 Russian (KVASAR) \\
\hline 4 & IAA & SLR & $x, y, U T 1$ & International network \\
\hline 5 & IAA & GPS & $x, y, U T 1$ & Mainly non-Russian \\
\hline 6 & IAA & VLBI & $x, y, U T 1, d \psi, d \varepsilon$ & International + 3 Russian (KVASAR) \\
\hline 7 & IAC & SLR & $x, y, L O D$ & International network \\
\hline
\end{tabular}

The basic stages of the method of combination processing according to Kaufman (2008) and Kaufman, Pasynok (2009) are:

- excluding of systematical errors;

- evaluation of average values EOP (RU);

- prediction;

- estimation of accuracy;

- generation of bulletins with the target data. 
The average of smoothed MMC series number 2 and 3 are used as a basis of Russian EOP system. For other series the regular amendments are estimated by exponential smoothing of EOP deviations of every series from basis values. After taking these amendments into account the averages of EOP values are formed using the weights which are calculated according to accuracy estimation for previous calendar year.

Calculations are conducted by three cycles:

- operative (ultra-rapid) $\mathrm{EOPq}(\mathrm{RU})$ values for the last day and predictions for the following of 30 days are evaluated every day;

- every Thursday saved measurements for the last calendar week are processed, the systematic errors of independent individual series are recalculated and the rapid EOPa(RU) values are evaluated;

- five weeks after end of the calendar month all saved measurements are processed and final values EOP (RU) are evaluated.

Such mode of calculations allows quickly, though with limited accuracy to provide the current EOP values and prediction, and then to refine them as far as new observation data become avialable. So, during calculation of operative and rapid EOP values only the limited set of the observations is used. In particular, VLBI data are not used for calculation of operative EOP values, since results of their measurements are accessible with a delay of few days.

The estimations of accuracy of operative, rapid and final EOP values for 2009 are resulted in Table 4.

Table 4. Accuracy of combined EOP solutions EOP(RU) of Russian Service

\begin{tabular}{|l|c|c|c|c|c|c|c|c|}
\hline \multirow{2}{*}{ Solution } & \multirow{2}{*}{$\begin{array}{c}\text { Latency } \\
\text { (days) }\end{array}$} & \multirow{2}{*}{$\begin{array}{c}\text { Type } \\
\text { estimation }\end{array}$} & \multicolumn{3}{|c|}{ RMS } & \multicolumn{3}{c|}{ Bias } \\
\cline { 4 - 10 } & & UT1 & \multicolumn{2}{|c|}{$\mathrm{x}$} & \multicolumn{2}{|c|}{$\mathrm{y}$} & $\mathrm{UT}$ & \multicolumn{2}{c|}{$\mathrm{x}$} & $\mathrm{Y}$ \\
\hline Operative & 1 & internal & 0.015 & 0.04 & 0.04 & & & \\
EOPq(RU) & & external & 0.049 & 0.15 & 0.20 & +0.002 & +0.11 & -0.11 \\
\hline Rapid & 4 & internal & 0.025 & 0.13 & 0.11 & & & \\
EOPa(RU) & & external & 0.023 & 0.13 & 0.18 & 0.000 & +0.07 & -0.12 \\
\hline Final & \multirow{2}{*}{35} & internal & 0.019 & 0.10 & 0.09 & & & \\
EOP(RU) & & external & 0.018 & 0.13 & 0.18 & 0.000 & +0.04 & -0.13 \\
\hline
\end{tabular}

The RMS values for estimation based on internal convergence are counted up under the formula:

$$
m_{\mathrm{C}}=\sqrt{\sum_{j} p_{j} v_{j}^{2} / n \sum p_{j}}
$$

where:

- $j$ - the numbers of individual EOP series listed in Table 3;

$-v_{j}$ - deviations of individual daily EOP values from combined one;

$-p_{j}$ - the weights of individual EOP values.

The deviations of MMC values of UT1 from IERS EOPC04 data are shown on Fig. 1 by red color: operative EOPq (RU) (the top graph) and rapid EOPa (RU) (the bottom one). For comparison, the similar deviations of UT1 values published by IERS Rapid Service/Prediction Center (USNO, http://maia.usno.navy.mil) every day (files finals.daily) and weekly (Bulletins A) are shown by blue color. It is visible that the MMC and IERS rapid EOP data are similar. 

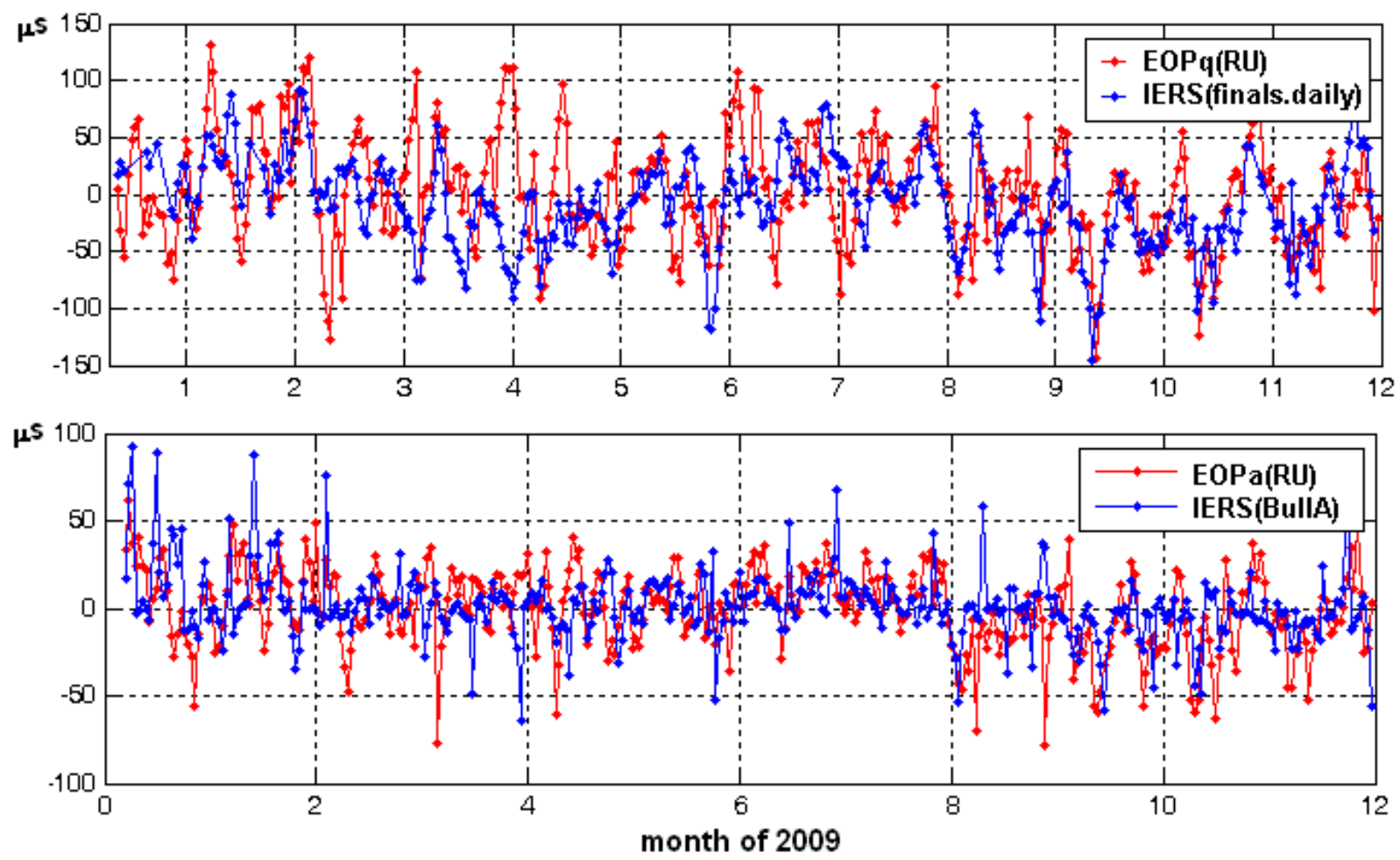

Fig. 1. Deviation UT1 of EOPq(RU) and EOPa(RU) series from EOPC04

\section{BULLETINES}

The operative, rapid and final EOP values are published in bulletins MMC of three corresponding series: Q, A and E.

Bulletin Q is issued daily at $6^{\mathrm{h}}$ UTC. It contains the values $\operatorname{EOPq}(\mathrm{RU})$ for last day and the prediction data for next 30 days. The bulletins are accessible only in electronic form (ftp.imvp.ru/Out_data/Bul_rus_Q/).

Bulletin A is issued every Thursday. It contains daily values $\operatorname{EOPa}(\mathrm{RU})$ for the last calendar week and the forecast for 7 next weeks. One release within each month contains finals values EOP(RU) in addition. Bulletins $A$ are accessible in electronic form (ftp.imvp.ru/Out_data/Bul_rus_A/) and in printed one (disseminated on requests mark@imvp.ru).

Bulletin $\mathrm{E}$ is issued in the form of the brochure one times in 3 months. It contains final values $\mathrm{EOP}(\mathrm{RU})$ and also the additional information (the lengths of day and Earth rotation velocity, comparison with EOP IERS, and also the individual EOP series calculated by MMC, IAA and IAC using the VLBI, GPS and SLR observations). Last bulletin E of each year in addition contains the short annual report. Bulletin E extends on requests.

\section{CONCLUSIONS}

The main directions of EOP activity of the Russian State Time, Frequency and Earth Rotation Service are presented. More information one can find by anonymous access on addresses ftp.imvp.ru and www.vniiftri.ru. 


\section{REFERENCES}

Kaufman M. (2008) Precise measurements for high technologies, Monography eds. Krasovsky P., Mendeleevo 2008, 80-118 (in Russia).

Kaufman M., Pasynok S. (2009), Proceeding of All-Russian conference KVNO - 2009, eds. Finkelstein A., S.-Petersburg, 2009, 240-244 (in Russian).

Received: 2010-05-14,

Reviewed: 2010-06-30, by B. Luzum,

Accepted: 2010-09-27 